\title{
60 YEARS OF URBAN DEVELOPMENT IN DENIA AND ITS INFLUENCE ON THE MARINETA CASSIANA BEACH
}

\author{
A.J. TENZA-ABRIL ${ }^{1}$, J.I. PAGÁN ${ }^{1}$, L. ARAGONÉS ${ }^{1}$, J.M. SAVAL ${ }^{1}$, J.C. SERRA ${ }^{2}$ \& I. LÓPEZ ${ }^{1}$ \\ ${ }^{1}$ Dept. of Civil Engineering, University of Alicante, Spain. \\ ${ }^{2}$ Dept. of Transportation, Polytechnic University of Valencia, Spain.
}

\begin{abstract}
Everyone is aware of the special relationship that man has with the coast; from the beginning of mankind, humans have been attracted to the littoral zone for the construction of settlements and the use of its resources. Subsequently, humans have evolved, leaving an increasingly large footprint on this medium. Hence, there is a need to deepen our knowledge to protect against the threat that we ourselves pose. Coastal regression mainly due to the lack of sediment is a global problem. The environmental, economic and social interest makes the study of coastal regression a major problem in the institutions. This article places the study area in Denia (Alicante, Spain). In this population, for some time, there has been concern about the effect on the beaches of the sharp erosion of the coastline. The Marineta Cassiana beach has been chosen for this study because of its special location and the set of elements of the environment. Thus, with respect to the beach study, it is observed that the land beside it is a fully urbanized area, which has suffered due to the pressure of development in this area since 1956, limited as it is by background mountains. Therefore, this study encompasses different aspects of the regression of the coast. To this end, a study of the historical evolution of the beach since 1956 has been carried out. The hydrological modelling of river basins discharging to the beach and their changes due to the alteration of the landscape has been carried out, using dynamics and morphological characterization of the area and an analysis of the erosion of these basins. Also, the historical evolution of the surf on the beach, as well as changes in the morphology of the coast, which have influenced the marine climate, have been taken into account.
\end{abstract}

Keywords: GIS, Posidonia oceanica, shoreline, urban development.

\section{INTRODUCTION}

Coastal zones have been occupied since time immemorial because they have abundant resources [1]. Coastal villages were built in relation to fishing activities. Nicholls and Small [2] estimated that $23 \%$ of the world's population live $100 \mathrm{~km}$ from the coast and within $100 \mathrm{~m}$ of sea level.

Coastal shorelines are naturally dynamic in response to coastal processes. Land-use change associated with coastal urban development and growing human population accelerates coastal shoreline change [3]. The risks associated with anthropogenic pressures have been widely reviewed in literature [4-6].

The shoreline is where the land and sea meet. Its study is used by many coastal engineers to analyse the sedimentary trend of the beach [5]. Aerial photographs or high-resolution satellite images are sources used to reference the shoreline position from different dates and can be useful to measure and analyse the beach's rate-of-change. External factors such as rain on urbanized areas can affect beaches because the discharge increases.

In addition, other resources can be affected due to the anthropogenic actions. Posidonia oceanica is the most common seagrass species in the Mediterranean Sea and its leaves atten- 


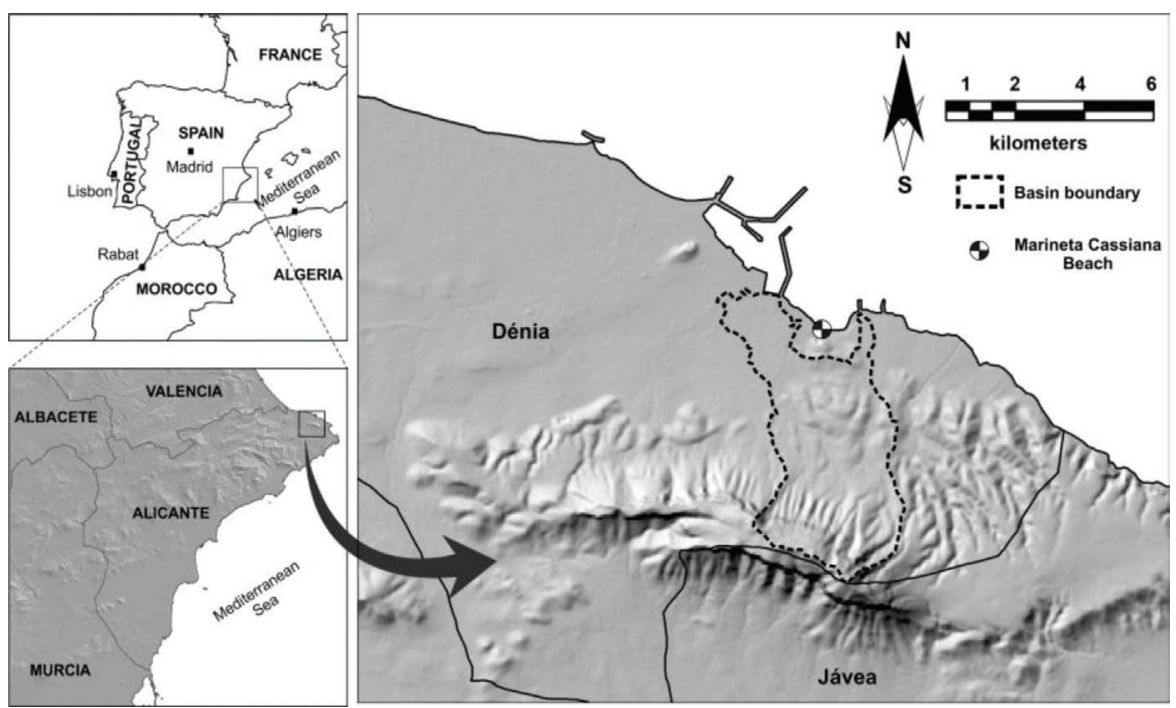

Figure 1: Location of study area, with delimited catchment studied.

uate waves and current action, thereby increasing sedimentation. Human actions can affect the zones in which the species are distributed $[7,8]$.

The aim of this study is to quantify historical shoreline changes along Marineta Cassiana beach between 1956 and 2014 and the effects of the impacts on the beach due to the urban development carried out over the last 60 years.

\section{STUDY AREA}

\subsection{Location and history}

Marineta Cassiana beach is located in Denia, Northern Alicante (Spain), as can be seen in Fig. 1. The area is composed of two main units: (i) the Marquesado plain and (ii) Montgó Massif (753 m.a.s.1.).

Marineta Cassiana beach (1,260 $\mathrm{m}$ length and $30 \mathrm{~m}$ width) is bordered by intensive urban pressure on its south side and limited by the port of Denia on its west side and by breakwater on the east. The Marineta Cassiana catchments are compounds of limestone, calcarenite, bioclastic limestone, sandy loam and dolomite rocks [9].

Nearby, $P$. oceanica forms vast meadows on the seabed of the Mediterranean Sea. There are two ravines that discharge into Marineta Cassiana beach (Santa Lucía and L'Emboixar). Table 1 shows the main parameters for hydrological study. Both ravines only have active flows during stormy events.

\subsection{Climatology}

The climate of Denia is classified as a Mediterranean semi-arid climate, with warm temperatures all year round and scarce rain. The annual average temperature is $17^{\circ} \mathrm{C}$, the minimum being $2^{\circ} \mathrm{C}$ (January and February) and the maximum $35^{\circ} \mathrm{C}$ (July and August). Annual average precipitation is up to $600 \mathrm{~mm}$. 
Table 1: Santa Lucía and L’Emboixar ravine properties.

\begin{tabular}{lccccc}
\hline & \multicolumn{5}{c}{ Basin attributes } \\
\cline { 2 - 6 } Basin & Area (Ha) & $\begin{array}{c}\text { Max. flow } \\
\text { length (km) }\end{array}$ & $\begin{array}{c}\text { Upstream } \\
\text { height }(\mathbf{m})\end{array}$ & $\begin{array}{c}\text { Downstream } \\
\text { height }(\mathbf{m})\end{array}$ & $\begin{array}{c}\text { Average slope } \\
(\mathbf{m} / \mathbf{m})\end{array}$ \\
\hline Santa Lucía & $296.19 / 220.71^{*}$ & 4.12 & 677 & 0 & 0.17 \\
L'Emboixar & $179.77 / 106.82^{*}$ & 4.44 & 749 & 0 & 0.17 \\
\hline
\end{tabular}

*Area excluding the protected natural area of Montgó Massif.
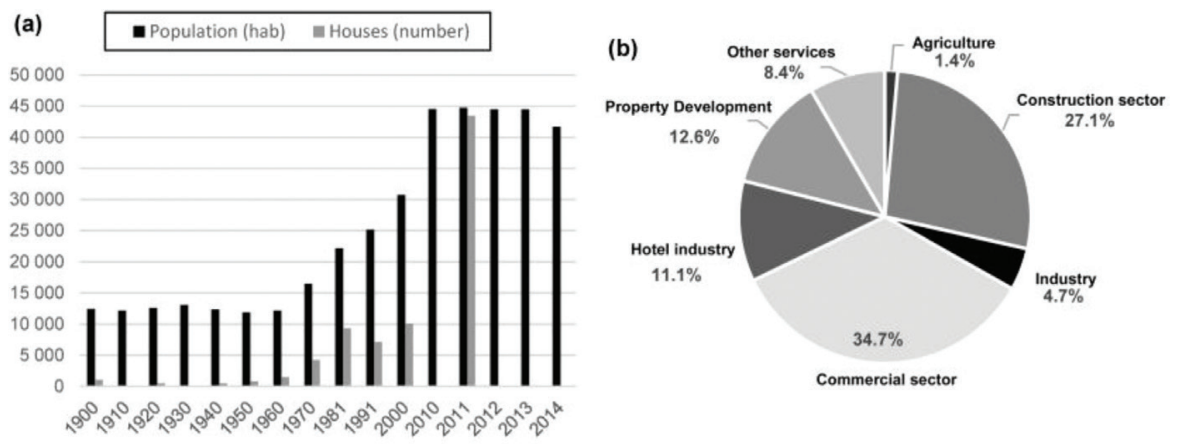

Figure 2: (a) Population from 1900 to 2014 and number of houses, (b) economic sectors.

\subsection{Demography and economic sectors}

Denia is a municipality focused on economic activities related to tourism. Since the 1960s, Denia has passed through a strong phase of urban development, mainly due to residential tourism, which has caused a broad transformation in both the economy and land use [10]. These changes in land use cause alterations in the hydrological behaviour of the catchments causing risks, increasing the speed of water flow and the soil erosion [11].

As can be seen in Fig. 2, there are two distinct periods in population growth. Until 1950 there is moderate population growth; from 1960 there is a rapid increase in population. The tourism boom was responsible for the fast growth in population and the economy. In addition, the traditional economy was based on the agricultural sector (citrus fruits, grape export and maritime transportation). At the moment, Denia is focused on a tourism-based economic model. For that reason, the number of houses has been growing over the last 50 years.

The economic expansion caused significant land-use changes. Urban development from 1960 resulted in the total occupation of the basin studied.

\subsection{Beach morphology and history}

Marineta Cassiana beach was historically formed by pebbles, but a series of anthropic actions has changed its morphology: (i) In 1985, a first beach nourishment of $67,000 \mathrm{~m}^{3}$ was carried out with medium sands; (ii) a breakwater of $170 \mathrm{~m}$ length was built at the eastern part of the beach in 1987 and (iii) a second beach fill of $25,500 \mathrm{~m}^{3}$ was carried out. Nowadays, the backshore sediment grain size is medium sands $\left(\mathrm{D}_{50}\right.$ equal to $\left.0.350 \mathrm{~mm}\right)$. 


\section{METHODOLOGY}

\subsection{Data gathering}

Elevation, geological, land use, bathymetry, sediment, morphology and biocoenosis data were gathered from the seabed and beach, as well as aerial imagery of the study area in different periods of time (Table 2). To manage and store all the information available from different sources and formats, a geographical database was created. Geodatabases have a powerful capability to create queries and link spatial and attribute data for analytical purposes in a GIS (Ggeographic information system) environment.

Table 2: Type, date, format, resolution and source of data used in this research.

\begin{tabular}{lc}
\hline Data type & Date \\
\hline Digital elevation model & 2009 \\
National topographical map & 1950 \\
Land cover. SIOSE 2005 & 2005 \\
Land uses map & $1980-1990$ \\
Forestal map & $1997-2006$ \\
Aerial images (photograms) & $1956,1977,1989,1996$ \\
Orthophotos & $2000,2005,2014$ \\
Bathymetry & 2006 \\
Seabed sediment and morphology & 2006 \\
\hline
\end{tabular}

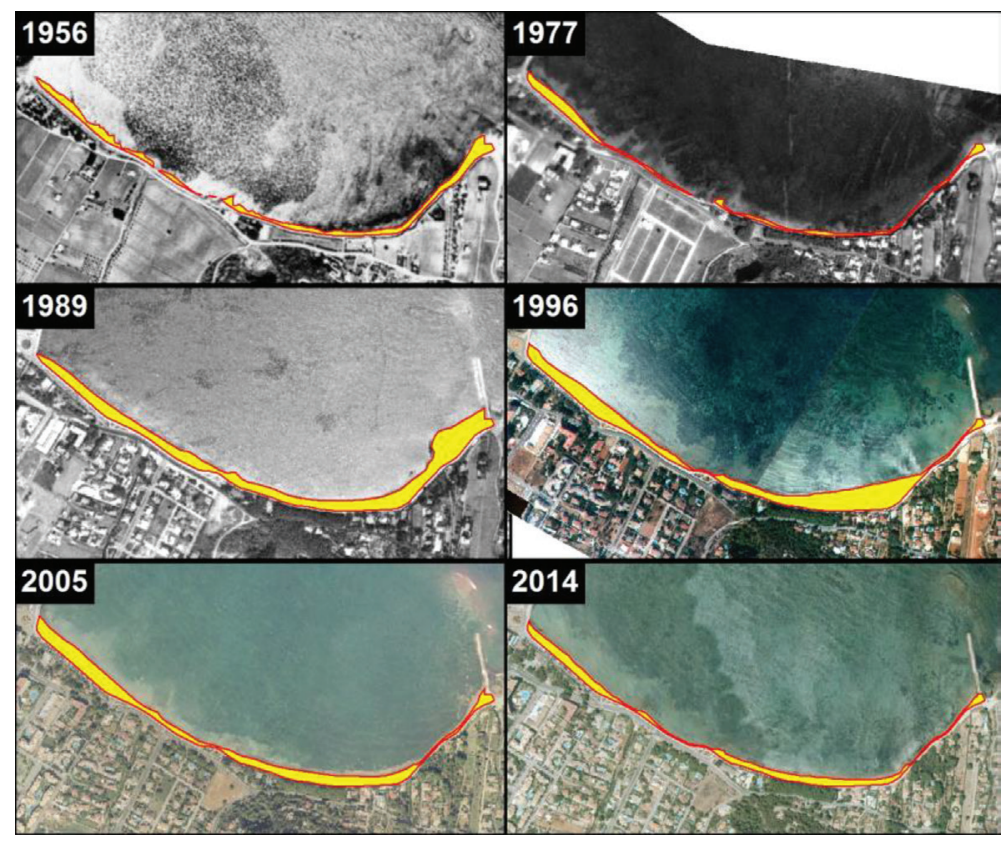

Figure 3: Shoreline evolution in the period of time studied. 


\subsection{Historical urban development and shoreline evolution}

Urban development and shoreline evolution in the period studied have been vectorised using GIS software manually. A series of georeferenced aerial images and orthophotos was used to analyse changes produced in land use and in the Marineta Cassiana shoreline (Fig. 3). The analysis allows the rapid development of urban land use and the shoreline trend in the period of time studied to be observed.

\subsection{Hydrological study}

Changes in the basins (Santa Lucía and L'Emboixar) that discharge into Marineta Cassiana beach were obtained to observe discharge evolution over the last 60 years. Three different scenarios were studied (1950, 1981 and 2005). Precipitation data were obtained from Agencia Estatal de Meteorología (AEMET).

The runoff Curve Number method (CN) developed by the USDA Natural Resources Conservation Service (formerly SCS), was used because it is widely employed in the prediction of approximate amount of runoff from a given rainfall event.

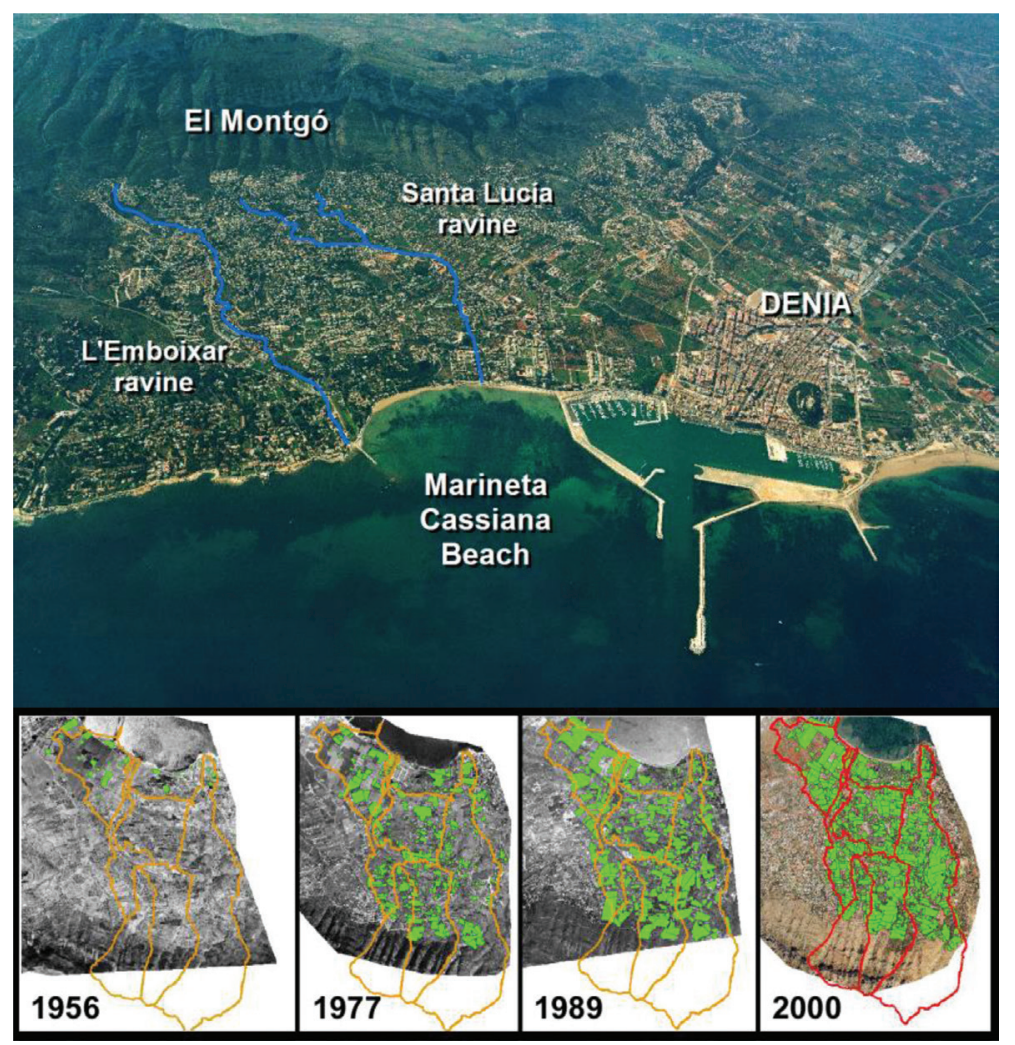

Figure 4: Aerial view of the basin in 1998, with almost all the surface urbanized. 
Table 3: Urban development from 1956 to 2000 in the study area.

\begin{tabular}{llcccc}
\hline & & \multicolumn{4}{c}{ Urbanized area } \\
\cline { 3 - 6 } Basin & Area (Ha) & $\mathbf{1 9 5 6}(\mathbf{H a})$ & $\mathbf{1 9 7 7}(\mathbf{H a})$ & $\mathbf{1 9 8 9}(\mathbf{H a})$ & $\mathbf{2 0 0 0}(\mathbf{H a})$ \\
\hline Santa Lucía & $296.19 / 220.71^{*}$ & 6.93 & 59.36 & 87.61 & 127.21 \\
L'Emboixar & $179.77 / 106.82^{*}$ & 1.77 & 20.46 & 35.17 & 110.56 \\
\hline
\end{tabular}

*Area excluding the protected natural area of Montgó Massif.
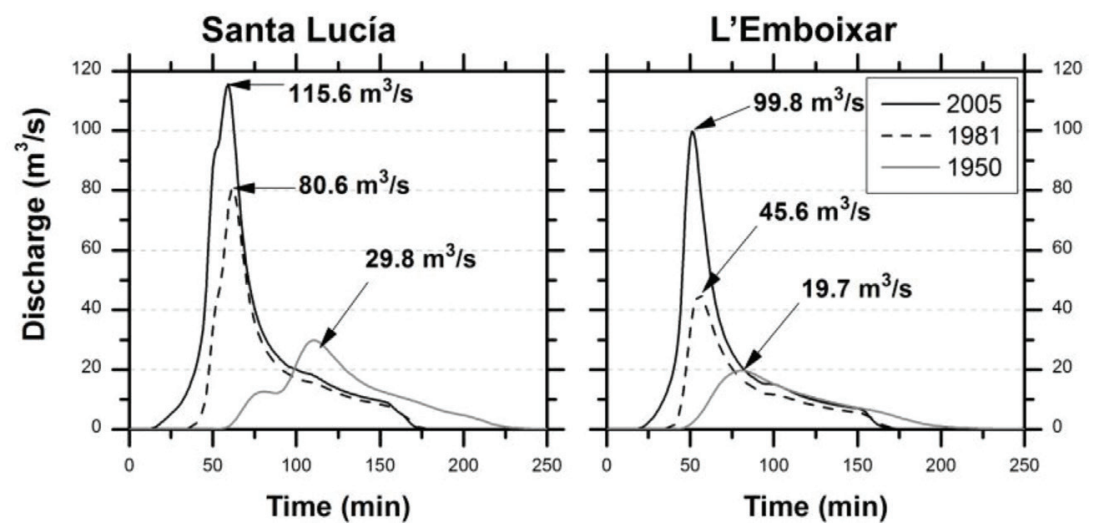

Figure 5: Hydrograph of Santa Lucía and L'Emboixar in the three scenarios studied (1950, 1981 and 2005) for 25-year return period.

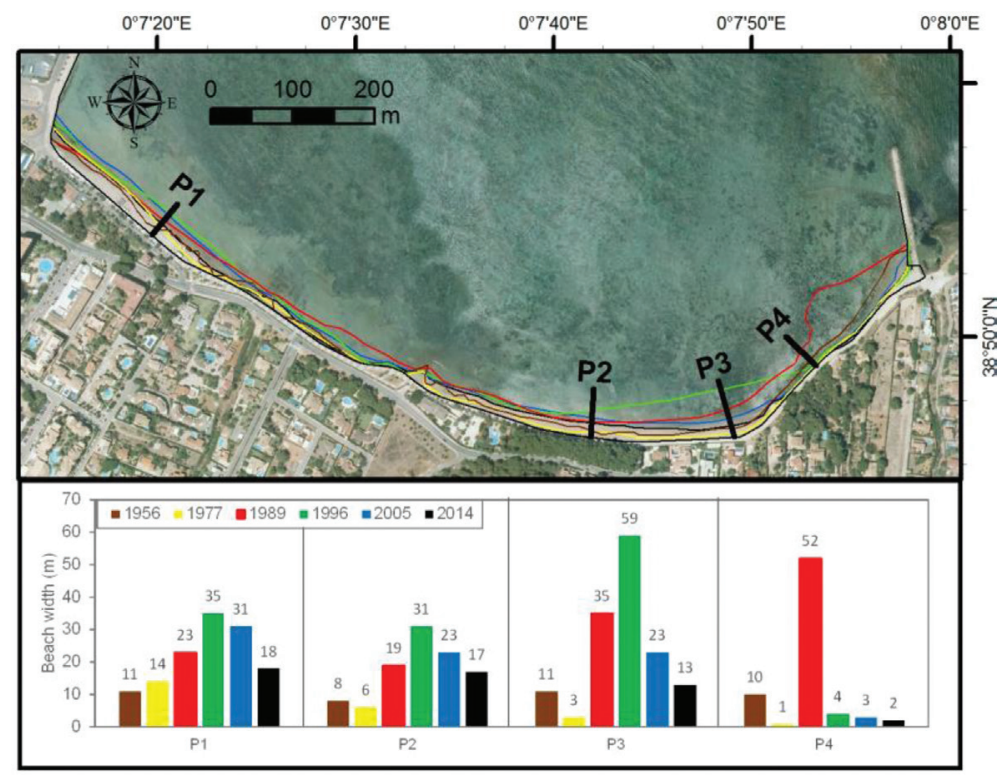

Figure 6: Shoreline evolution in the period of time studied. Beach width change at selected profiles. 
324 Urban Regeneration and Sustainability

\section{RESULTS AND DISCUSSION}

Between 1956 and 2000, the urbanized areas obtained from aerial imagery have increased exponentially, almost fully covering the catchments, up to the limits of the protected area of Montgó Massif, as can be seen in Fig. 4 and Table 3.

The hydrographs calculated for the three periods studied are shown in Fig. 5. The runoff has been strongly affected by the results of the urban development process; therefore, limited soil is available. Also, the water flows through faster, owing to the less surface roughness, as can be seen in Fig. 5. Time to peak flood has been reduced to about 50 and 25 minutes, respectively, in the Santa Lucía and L'Emboixar basins, since 1950, in the 25-year return period studied.

The urbanized area has increased by $2,631 \%$ from 1956 to 2000 . This means that $100 \%$ of the available area is urbanized today. This unsustainable urban development has led to an increase in the drainage capacity of the ravines but a decrease in the erosive capability of the rains in the catchment. The lack of maintenance of the streambeds, together with an excessive proliferation of vegetation, ensured that a major part of the coarse fraction of the eroded sediments does not reach the beach.

The increase of the water flow has caused the coarse sediments to be moved offshore, leading to an increment in the shoreline erosion. The beach nourishments carried out in the $1980 \mathrm{~s}$ have modified the beach profile; thereby, it has become less steep. The change in the sediment grain-size distribution (from pebbles to sand) and the excess of the supplied volume has affected the $P$. oceanica meadow. Moreover, the change in the longshore transport due to the construction of the breakwater has led to an important imbalance of the beach (Fig. 6). A regressive movement of the position of the $P$. oceanica during the studied period has been detected, from being settled very close to the shoreline to currently being located at $470 \mathrm{~m}$ offshore and $4.2 \mathrm{~m}$ depth (Fig. 7).

\section{CONCLUSIONS}

Significant changes have occurred over the last 60 years in the area studied. Unsustainable urban development has caused many changes that directly affect the beach's evolution. Firstly, the almost total urbanization of the surface has caused a decrease in the erosive

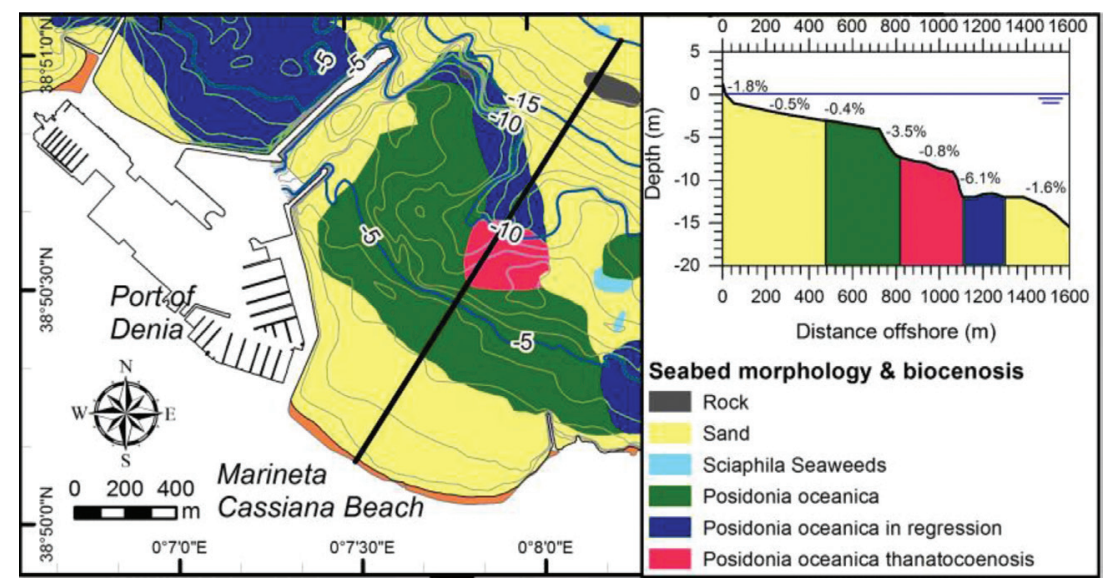

Figure 7: Seabed morphology and biocoenosis, with bathymetry (left) and beach profile with slopes (right). 
capability of the ravines but an increase in the water flow speed. This has led to a lack of sediment supply to the beach and the increase in the shoreline regression.

A close relationship between the loss of beach surface and the urban development can be stated. Secondly, the anthropic actions carried out in the 1980s have altered the beach morphology. The nourishments changed the beach sediment from pebbles to sand. Although the beach fill increased the beach area, the decision to create a more attractive tourist beach formed of sands has led to an important imbalance in the studied area. In addition, the damage to the $P$. oceanica meadow due to the excessive sand volume supplied has caused an increase in the regression rate of the shoreline. This research has underlined the adverse consequences of unsustainability decisions on a fragile environment such as our coasts.

\section{ACKNOWLEDGEMENTS}

We are grateful to Servicio Provincial de Costas de Alicante (Ministerio de Agricultura y Medio Ambiente), Puertos del Estado and Ayuntamiento de Denia for the useful information provided; we also express our gratitude to the University of Alicante.

\section{REFERENCES}

[1] Misra, A. \& Balaji, R., Decadal changes in the land use/land cover and shoreline along the coastal districts of southern Gujarat, India. Environmental Monitoring and Assessment, 187(7), p. 461, 2015. http://dx.doi.org/10.1007/s10661-015-4684-2

[2] Nicholls, R.J. \& Small, C., Improved estimates of coastal population and exposure to hazards released. Eos, Transactions American Geophysical Union, 83(28), pp. 301$305,2002$. http://dx.doi.org/10.1029/2002EO000216

[3] Nguyen, H.H., McAlpine, C., Pullar, D., Leisz, S.J. \& Galina, G., Drivers of coastal shoreline change: case study of Hon Dat coast, Kien Giang, Vietnam. Environmental Management, 55(5), pp. 1093-1108, 2015. http://dx.doi.org/10.1007/s00267-015-0455-7

[4] Clark, J., Coastal Zone Management Handbook, CRC Press/Lewis Publishers: Boca Raton, Florida, USA, p. 720, 1996.

[5] Defeo, O., McLachlan, A., Schoeman, D.S., Schlacher, T.A., Dugan, J. \& Jones, A., Threats to sandy beach ecosystems: a review. Estuarine, Coastal and Shelf Science, 81, pp. 1-12, 2009. http://dx.doi.org/10.1016/j.ecss.2008.09.022

[6] Schlacher, T.A., Dugan, J., Schoeman, D.S., Lastra, M., Jones, A., Scapini, F., McLachlan, A. \& Defeo, M., Sandy beaches at the brink. Diversity and Distributions, 13, pp. 556-560, 2007. http://dx.doi.org/10.1111/j.1472-4642.2007.00363.x

[7] Aragonés, L., Pagán, J.I., López, M.P. \& García-Barba, J., The impacts of Segura River (Spain) channelization on the coastal seabed. Science of the Total Environment, 543, pp. 493-504, 2016. http://dx.doi.org/10.1016/j.scitotenv.2015.11.058

[8] Aragonés, L., García-Barba, J., García-Bleda, E., López, I. \& Serra, J.C., Beach nourishment impact on Posidonia oceanica: case study of poniente beach (Benidorm, Spain). Ocean Engineering, 107, pp. 1-12, 2015.

http://dx.doi.org/10.1016/j.oceaneng.2015.07.005 
326 Urban Regeneration and Sustainability

[9] IGME. Instituto Geológico y Minero Español, available at http://info.igme.es/visorweb/

[10] Morote, Á.F. \& Hernández, M., Urban sprawl and its effects on water demand: a case study of Alicante, Spain. Land Use Policy, 50, pp. 352-362, 2016. http://dx.doi.org/10.1016/j.landusepol.2015.06.032

[11] Salvadore, E., Bronders, J. \& Batelaan, O., Hydrological modelling of urbanized catchments: a review and future directions. Journal of Hydrology, 529, pp. 62-81, 2015. http://dx.doi.org/10.1016/j.jhydrol.2015.06.028 